\title{
New Genotypes of Basella rubra and Basella alba Acclimatized and Bred at Vegetable Research and Development Station Buzău
}

\author{
Bianca Elena TĂNASE*, Costel VÎNĂTORU, Ovidia AGAPIE, Elena BARCANU, Geanina NEGOȘANU, Ion \\ GHERASE
}

Vegetable Research-Development Station Buzau, 23 Mestecanului St, Buzau, Romania

*corresponding author: biancae.tanase@yahoo.com

BulletinUASVM Horticulture 77(2) / 2020

Print ISSN 1843-5254, Electronic ISSN 1843-5394

DOI:10.15835/buasvmcn-hort: 2020.0045

\begin{abstract}
Basella alba is an underutilized plant with great food and medicinal potential, newly acclimatized in Romania at Vegetable Research and Development Station (VRDS) Buzau. For over 10 years, the Genetic, Breeding and Biodiversity Laboratory has studied a number of 12 genotypes from Basella spp. of these, two accessions (L5 and L8) showed distinct phenotypic feature. The experience has been done in randomized blocks with three replications, and the number of plants analyzed for each variant was 50. On L8 accession, the anthocyanin coloration was not present, unlike accession L5 which features a strong anthocyanin coloration, especially along the stem and on the dorsal side of the leaf. Specifically B. alba var. rubra shows a leaf width of $14.8 \mathrm{~cm}$ and a weight of $20 \mathrm{~g}$, and the B. alba shows a leaf width of $21.4 \mathrm{~cm}$ and a weight of $27.5 \mathrm{~g}$. Basella alba recorded the highest percentage in dry matter in the smallest leaves, namely $7.69 \%$ and Basela alba var. rubra registered the highest percentage in dry matter also in the small leaves, of $7.98 \%$. The aim of this study was to assess the morphological traits in order to patent a new acclimatized species in Romania. The study was finalized with one variety (L5) that has been successfully qualified for DUS test (Distinction, Uniformity and Stability) and soon will be registered in the Official Catalogue of Species and Varieties of Cultivated Plants.
\end{abstract}

Keywords: Basella spp., breeding, feature, phenotype

\section{Introduction}

Basella alba L. (Synonym: Basella rubra $R o x b$.) is an extremely heat tolerant (Grubben and Denton, 2004), fast growing perennial vine which belongs to the Basellaceae (Chenopodiaceae) family (Rathee et al., 2010). It is commonly known as Malabar spinach, Indian spinach, Ceylon spinach, vine spinach (Roy et al., 2010), climbing spinach (Sen et al., 2010), East-Indian spinach, Chinese spinach (Bamidele et al., 2010) and cyclone spinach (Nirmala et al., 2011). The plant has numerous secondary shoots (over 100). It's thick, semi-succulent, heart-shaped leaves have a mild flavor and mucilaginous texture. It is rich in vitamins $\mathrm{A}$ and $\mathrm{C}$, iron and calcium. It has been shown to contain certain phenolic phytochemicals, and it has antioxidant properties. Basella is known for its medicinal properties. Hydroxy-benzoic acids, hydroxyl-cinnamic acids, flavone groups were identified and characterized from the aqueous extract of Basella alba and Basella alba var. rubra species, values of phenolic as well as antioxidant activities were noted from B. alba species extract (Kumar et al., 2018). The roots are astringent but can be prepared and used as a treatment for the stomach. Natural dye can be 
extracted from the fruits, the reddish purple color being used in the pigmentation of various cakes, sweets, candies. The plant can be successfully cultivated for ornamental purposes, especially the red form, due to its vigorous appearance and lush and beautifully coloured foliage (Vînătoru et al., 2019).

The aims of this study were: acclimatization of the species, obtaining stable genotypes, elaboration of culture technology and finally approval and patenting of the accessions.

\section{Materials and methods}

VRDS Buzau has tradition in acclimatizing and breeding new species in Romania. Research began with the acquisition of the initial basic material for acclimatization and breeding. The main sources of genetic material were cultivars from India, New Zealand, Germany and China. For over 10 years, 12 accessions were subjected to intensive breeding work and after phenotypic evaluation two accession were retained L5, variety of B.alba var. rubra and L8, variety of B. alba. The experience has been done in randomized blocks with three repetitions, and the number of plants analyzed for each variant was 50 .

The experiment was conducted in the research site of VRDS Buzau. The seeds were sown in the second decade of March, in alveolar pallets with 70 cubes and volume of $50 \mathrm{~mL} /$ cube in a mixture of peat. The planting was made in May and the planting scheme used was $100 \mathrm{~cm}$ between rows and $40 \mathrm{~cm}$ between plants/row, in fenced system.

Throughout the vegetation period, biometric observations were made for 13 qualitative descriptors and 12 quantitative descriptors according to UPOV Guidelines.

The quantitative traits analyzed were: plant height $(\mathrm{PH})$, stem diameter (SD), number of leaves/plant (NL/P), leaf length (LL), leaf width (LWi), leaf weight (LWe), petiole length (PL), petiole diameter (PD), number of flowers (NF), flower length (FL), fruit diameter (FD), yield/ plant $(\mathrm{Y} / \mathrm{P})$ and the qualitative traits were: plant growth habit, stem pubescence, stem branching, leaf shape, blade shape of mature leaf, intensity of anthocyanin coloration, leaf colour, intensity of green colour of leaf, flower colour, fruit colour at physiologic maturity, fruit shape, main colour of seeds, seed coat texture.
In order to establish the relationship between accessions, statistical analysis was performed and ANOVA was used, followed by the Duncan's multiple range test.

The content in dry matter was measured on three different maturity stages of leaves (small leaf - 14 days after transplanting; medium leaf - 37 days after transplanting; large leaf - 60 days after transplanting), using the moisture analyzer Kern DBS60-3. The total soluble solid content of the leaf was measured with Optech refractometer.

\section{Results and discussion}

The analysis of climatic conditions of 2019 (Tab. 1) showed that the mean monthly temperatures increased from $22.5^{\circ} \mathrm{C}$ in May to $29.5^{\circ} \mathrm{C}$ in August, in contrast, the rainfall has experienced a decline from $71 \mathrm{~mm}$ in May to $25 \mathrm{~mm}$ in September. In comparison with the multiannual mean, it was noticed that the year 2019 had lower temperature than mean, but it was registered a greater amount of precipitations.

Following biometric measurements and descriptive analyzes, it was found that there is a significant difference between B.alba and B.alba var. rubra both in terms of quantitative and qualitative characters. Thus, the descriptive analysis of the quantitative characteristics are presented in Table 2 and that of the qualitative characteristics, in Table 3 .

Significant differences in the size and weight of the leaf can be observed as a result of the measurements and determinations.

Specifically $B$. alba var. rubra shows a leaf width of $14.8 \mathrm{~cm}$ and a weight of $20 \mathrm{~g}$, and the $B$. alba shows a leaf width of $21.4 \mathrm{~cm}$ and a weight of $27.5 \mathrm{~g}$. The colour of leaf is light green in L8 and dark green in L5. The number of leaves per plant varies from 249 to 256 in the case of cultivar L5, and in the case of cultivar L8 from 175 to 182, which means that production per plant is between 4608 and $5478 \mathrm{~g}$ for L5, and for cultivar L8 is between 4550 to $5775 \mathrm{~g}$.

In order to establish a correlation between quantitative traits, a correlation matrix (Tab. 4) was made. It was observed that there was a strong correlation between number of leaves and plant height. The stem diameter has a positive influence on leaf and fruit length. On the other hand, leaf weight has strong positive correlation with leaf width, petiole diameter, flower length and, of course, yield. 
Table 1. Climatic conditions during the vegetation period

\begin{tabular}{lccccc}
\hline \multicolumn{1}{c}{ Temperatures/rainfall } & May & June & July & August & September \\
\hline Mean monthly temperatures $\left({ }^{\circ} \mathrm{C}\right) 2019$ & 22.5 & 27 & 30 & 29.5 & 19.5 \\
\hline Multiannual monthly temperature $\left({ }^{\circ} \mathrm{C}\right)$ & 23 & 26 & 29 & 29 & 18.5 \\
\hline Sum of rainfall $(\mathrm{mm}) 2019$ & 71 & 92 & 75 & 53 & 22 \\
\hline Multiannual mean of rainfall $(\mathrm{mm})$ & 68 & 84 & 65 & 51 & 25 \\
\hline
\end{tabular}

Table 2. Mean values and standard deviation of quantitative plant characteristics

\begin{tabular}{lcc}
\hline \multicolumn{1}{c}{ Character } & L5 \pm sd & L8 \pm sd \\
\hline Plant height $(\mathrm{cm})$ & $266 \pm 5,29 \mathrm{~b}$ & $249 \pm 6,55 \mathrm{a}$ \\
\hline Stem diameter $(\mathrm{cm})$ & $1,37 \pm 0,22 \mathrm{a}$ & $1,77 \pm 0,19 \mathrm{~b}$ \\
\hline Number of leaves/plant (pcs) & $251,66 \pm 3,78 \mathrm{~b}$ & $179 \pm 3,60 \mathrm{a}$ \\
\hline Leaf length $(\mathrm{cm})$ & $18,26 \pm 1,15 \mathrm{a}$ & $22,66 \pm 1 \mathrm{~b}$ \\
\hline Leaf width $(\mathrm{cm})$ & $14,8 \pm 1,56 \mathrm{a}$ & $21,4 \pm 0,91 \mathrm{~b}$ \\
\hline Leaf weight $(\mathrm{g})$ & $20 \pm 2 \mathrm{a}$ & $27,5 \pm 4,04 \mathrm{~b}$ \\
\hline Petiole length $(\mathrm{cm})$ & $3,43 \pm 065 \mathrm{a}$ & $2,86 \pm 0,75 \mathrm{a}$ \\
\hline Petiole diameter $(\mathrm{cm})$ & $0,60 \pm 0,02 \mathrm{a}$ & $0,80 \pm 0,14 \mathrm{~b}$ \\
\hline Number of flowers/inflorescence & $21 \pm 3 \mathrm{a}$ & $23,33 \pm 1,15 \mathrm{a}$ \\
\hline (pcs) & $0,29 \pm 0,01 \mathrm{a}$ & $0,7 \pm 0,01 \mathrm{~b}$ \\
\hline Flower length (cm) & $0,79 \pm 0,01 \mathrm{a}$ & $0,83 \pm 0,02 \mathrm{~b}$ \\
\hline Fruit diameter $(\mathrm{cm})$ & $5,028,66 \pm 435,70 \mathrm{a}$ & $5241,66 \pm 627,66 \mathrm{a}$ \\
\hline Yield/plant $(\mathrm{g})$ & &
\end{tabular}

Note: Different letters denote significant differences (Duncan test, $\mathrm{p}<0.05$ ).

Table 3. Qualitative plant characteristics

\begin{tabular}{|c|c|c|}
\hline Morphologic trait & L5 rubra & L8 alba \\
\hline Plant growth habit & Erect & Erect \\
\hline Stem pubescence & Sparse & Sparse \\
\hline Stem branching & Mixed & Mixed \\
\hline Leaf shape & Cordate & Ovate \\
\hline Blade shape of mature leaf & Circular & Circular \\
\hline Intensity of anthocyanin coloration & Strong & Absent \\
\hline Leaf colour & Green & Green \\
\hline Intensity of green colour (leaf) & Dark & Medium \\
\hline Flower colour & Dark pink & White-pink \\
\hline Fruit colour at physiologic maturity & $\begin{array}{l}\text { Black- } \\
\text { purple }\end{array}$ & Black-purple \\
\hline Fruit shape & Oblong & Oblong \\
\hline Main colour of seeds & Black & Dark maroon-black \\
\hline Seed coat texture & Rough & Rough \\
\hline
\end{tabular}


Table 4. Correlation matrix of main characters

\begin{tabular}{|c|c|c|c|c|c|c|c|c|c|c|c|c|}
\hline Variable & PH & SD & NL/P & LL & Lwi & Lwe & PL & PD & NF & FL & FD & $\mathbf{Y} / \mathbf{P}$ \\
\hline $\mathrm{PH}$ & 1 & & & & & & & & & & & \\
\hline SD & $-0,422$ & 1 & & & & & & & & & & \\
\hline $\mathrm{NL} / \mathrm{P}$ & 0,891 & $-0,702$ & 1 & & & & & & & & & \\
\hline LL & $-0,729$ & 0,915 & $-0,896$ & 1 & & & & & & & & \\
\hline Lwi & $-0,850$ & 0,698 & $-0,949$ & 0,918 & 1 & & & & & & & \\
\hline Lwe & $-0,908$ & 0,399 & $-0,905$ & 0,646 & 0,769 & 1 & & & & & & \\
\hline PL & 0,425 & $-0,568$ & 0,404 & $-0,570$ & $-0,385$ & $-0,340$ & 1 & & & & & \\
\hline PD & $-0,708$ & 0,553 & $-0,753$ & 0,701 & 0,709 & 0,748 & $-0,799$ & 1 & & & & \\
\hline $\mathrm{NF}$ & $-0,120$ & 0,579 & $-0,520$ & 0,447 & 0,371 & 0,446 & $-0,065$ & 0,378 & 1 & & & \\
\hline FL & $-0,882$ & 0,747 & $-0,997$ & 0,927 & 0,957 & 0,874 & $-0,434$ & 0,746 & 0,502 & 1 & & \\
\hline FD & $-0,479$ & 0,962 & $-0,735$ & 0,947 & 0,806 & 0,396 & $-0,523$ & 0,573 & 0,483 & 0,780 & 1 & \\
\hline $\mathrm{Y} / \mathrm{P}$ & $-0,451$ & $-0,344$ & $-0,305$ & $-0,122$ & 0,103 & 0,672 & 0,033 & 0,362 & 0,186 & 0,233 & $-0,385$ & 1 \\
\hline
\end{tabular}

Note: Values in bold are different from 0 with a significance level alpha $=0.05$
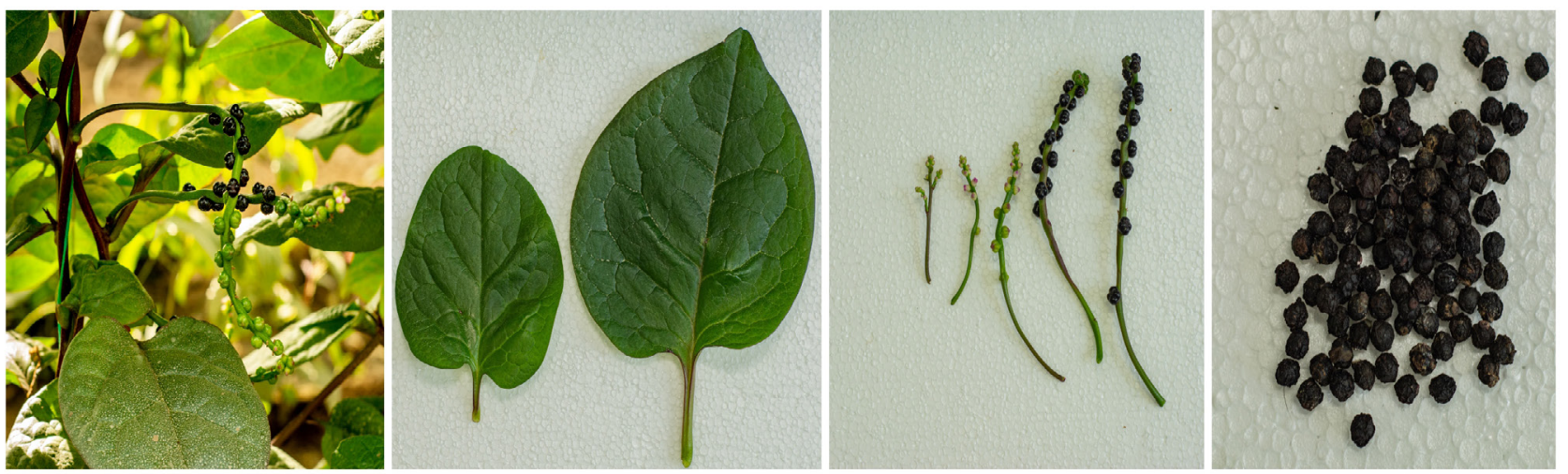

Figure 1. Plant details of Basella alba var. rubra (L5)
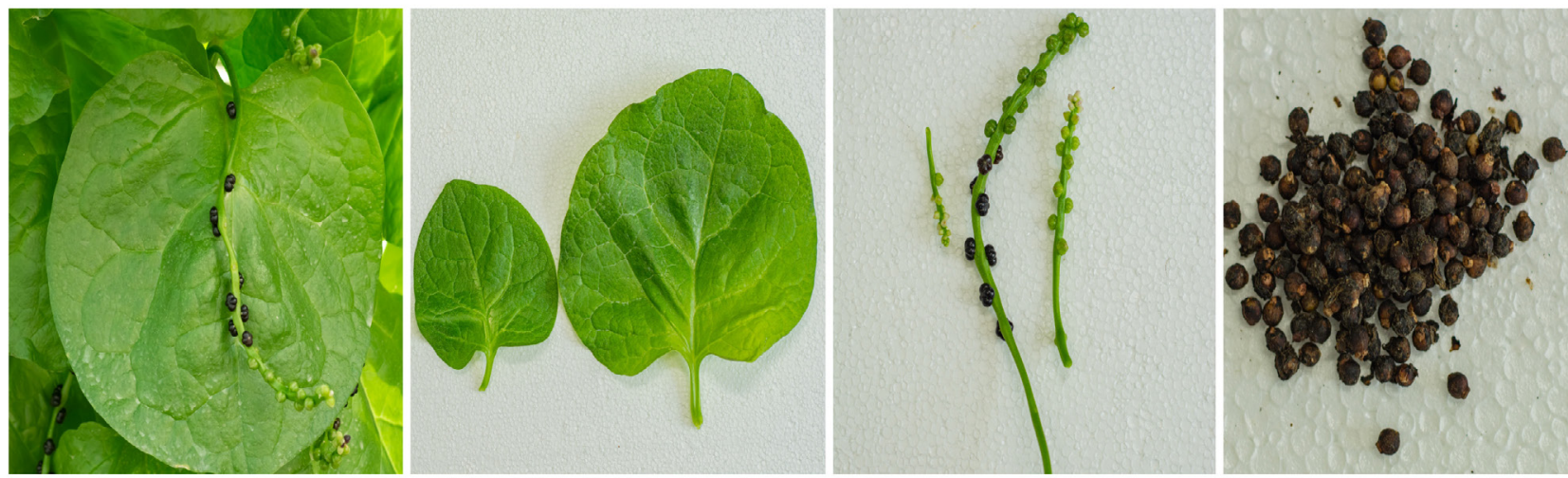

Figure 2. Plant details of Basella alba (L8) 


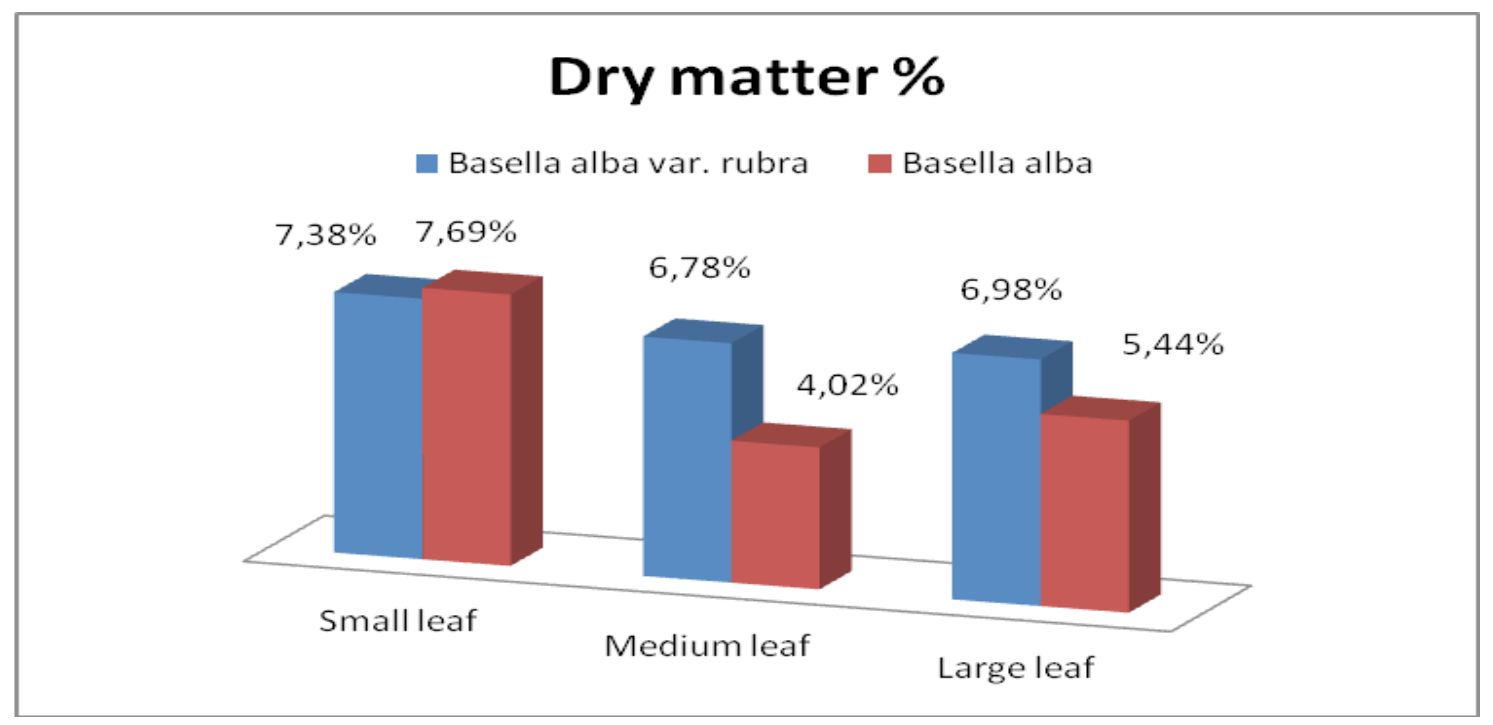

Figure 3. Dry matter content in Basella leaves

Regarding the qualitative traits, it was observed that on L8 accession, the anthocyanin coloration was not present (Fig. 2), unlike accession L5, which features a strong anthocyanin coloration especially along the stem and on the dorsal side of the leaf (Fig. 1). Seeds are black, globose, indehiscent and the coat texture is rough. Similar results were obtained by Deshmukh et al. (2014).

For both cultivars a number of three leaves of different maturity stages and size (small leaf - 14 days after transplanting; medium leaves - 37 days after transplanting; large leaves - 60 days after transplanting) were analyzed and it was found that Basella alba recorded the highest percentage in dry matter in the smallest leaves, namely $7.69 \%$, while the lowest percentage was recorded in mediumsized leaves, with a percentage of $4.02 \%$. Basella alba var. rubra registered the highest percentage in dry matter in the small leaves, of 7.98\%, while the lowest percentage was registered in the medium leaves, more precisely $6.78 \%$ (Fig. 3).

The total soluble solid content did not vary from one accession to another, or from one leaf to another. The recorded values ranged from 10 $11^{\circ}$ Brix.

\section{Conclusion}

The research ended with the establishment of a valuable germoplasm collection of Basella species. Two accessions have been acclimatized and bred, and of these L5 B.alba var. rubra is in the last year of tests at ISTIS Bucuresti. This varieties show distinct phenotypic feature that have successfully passed the DUS (Distincbility, Uniformity and Stabilization) test.

Acknowledgements. The work was supported by a grant of the Romanian Ministry of Research and Innovation, CCCDI - UEFISCDI, project number PN-III-P1-1.2-PCCDI-2017-0850/ contract 14 PCCDI/2018, within PNCDI III.

\section{References}

1. Bamidele O, Akinnuga AM, Olorunfemi JO, Odetolo OA, Oparaji CK, Ezelgbo N (2010). Effects of aqueous extract of Basella alba leaves on haematological and biochemical parameters in Albino rats. African Journal of Biotechnology, 9: 6952-6955.

2. Bioversity International (2007). Guidelines for the development of crop descriptor lists. Bioversity Technical Bulletin Series. Bioversity International, Rome, Italy. xii+72p.

3. Deshmukh SA, Gaikwad DK (2014). A review of the taxonomy, ethnobotany, phytochemistry and pharmacology of Basella alba (Basellaceae).

4. Grubben GJH, Denton OA (2004). Plant Resources of Tropical African vegetables. Wageningen; Backhuys Leiden (CTA). Wageningen: PROTA Foundation.

5. Kumar, BR, Anupam A, Manchikanti P (2018). Identification and characterization of bioactive phenolic constituents, anti-proliferative, and anti-angiogenic activity of stem extracts of Basella alba and rubra. Journal of Food Science and Technology 55: 1675-1684.

6. Nirmala A, Saroja S, Gayathri Devi G (2011). Antidiabetic activity of Basella rubra and its relationship: with the antioxidant property. British Biotechnology Journal, 1: 1-9. 
7. Rathee S, Ahuja D, Rathee P, Thanki M, Rathee D (2010). Cytotoxic and antibacterial activity of Basella alba whole plant: A relatively unexplored plant. Pharmacologyonline, 3: 651-658.

8. Roy SK, Gangopadhyay G, Mukherjee KK (2010). Is stem twining form of Basella alba L. a naturally occurring variant? Current Science, 98: 1370-1375.
9. Sen K, Goel A, Rawal S, Mahajan N, Baboo S, Alak S (2010). Antimicrobial activity of Basella rubra leaves. International Journal of Pharmaceutical Sciences and Research, 1: 88-91.

10. Vînătoru C, Mușat B, Bratu C (2019). Tratat de legumicultură specială. Editura ALPHA MDN, Buzău; pp. 513-520. 